\title{
Review on active building energy conservation using phase change materials
}

\author{
Dazhang Yang ${ }^{1,2,3}$, Naixin Wang ${ }^{1,2}$, Jing Xie ${ }^{1,2^{*}}$ and Jinfeng Wang ${ }^{1,4}$ \\ ${ }^{1}$ College of Food Science \& Technology, Shanghai Ocean University, Shanghai 201306, China. \\ ${ }^{2}$ Shanghai Professional Technology Service Platform on Cold Chain Equipment Performance and Energy Saving Testing Evaluation, \\ Shanghai 201306, China \\ ${ }^{3}$ Quality Supervision, Inspection and Testing Center for Cold Storage and Refrigeration Equipment, Ministry of Agriculture, Shanghai \\ 201306, China \\ ${ }^{4}$ National Experimental Teaching Demonstration Center for Food Science and Engineering (Shanghai Ocean University), Shanghai 201306, \\ China
}

\begin{abstract}
With a increasing application of phase change energy storage technology in the fields of building energy conservation, refrigeration, and air conditioning, the shortcomings of traditional phase change materials (PCMs) have become important, which seriously restricts the development of phase change cold storage technology. Therefore, the new phase change materials have become a research focus in the field of phase change energy storage. The classification and characteristics of phase change materials are briefly described in the paper. In addition, the active building energy-saving are reviewed.
\end{abstract}

\section{Introduction}

The phase change energy storage technology is used as a kind of new energy technology to conserve energy in industry and building domains. The development of phase change energy storage technology can be divided into two areas, the first step is to develop phase change materials (PCMs) with large latent heat and stable performance[1]. The application of advanced phase change technology equipment is the next step, mainly involving phase change heat transfer between energy storage elements[2], heat exchangers, and systems[3], and the convection coupling heat transfer between PCMs and fluids[4]. Material Corrosion also included. PCMs play an important role in phase-change technology. While studying traditional PCMs such as water, inorganic salts, organic, and metal materials[5], new trends of PCMs research have emerged, from inorganic to organic, single to combined, macroscopic to nano/microencapsulated[6] Applications of shape-stabilized PCMs[7] and microencapsulation PCMs [8]in building energy-saving and solar energy have become the research hotspot $[9,10]$

There are different types of PCMs, and they are classified according to different kinds of criteria. Based on substances, PCMs have been divided into four known as solid-solid PCMs[11], solid-liquid PCMs [12], solid-gas PCMs, and liquid-gas PCM. The solid-liquid PCMs is the most widely used PCMs in building. Moreover, based on underlying chemical nature, solid-liquid PCMs can be classified into organic PCMs, inorganic PCMs, and eutectic PCMs[13,14]. The organic PCMs can be divided into the paraffin and non-paraffin groups.

\section{Solid-liquid PCMs}

Solid-liquid PCMs are mainly reversible heat absorption and exotherm by solid-liquid phase change, which are utilized as one of the most common types of PCMs. This is because they consist of an increase in latent heat of capacity and smaller changes in volume during the transition of phase change compared to others. However, subcooling and phase separation cause leakage, contamination, corrosive, and expensive encapsulated containers.

Solid-liquid PCMs can be classified into organic PCMs and inorganic PCMs. Organic phase change materials (OPCM) has grabbed a lot of attention due to its excellent properties that can be combined with thermal energy storage systems to preserve renewable energy. Wei et al.[15] presented two new composite PCMs consisting of octadecane with myristic acid and palmitic acid with the latent heat of phase change of $236 \mathrm{~J} / \mathrm{g}$ and $238 \mathrm{~J} / \mathrm{g}$. Ghadim et al.[16] develop a new bio-based PCMs composed of six binary systems, namely 1-dodecanol (DD) + methyl stearate (MES), DD + methyl palmitate (MEP), DD + methyl laurate (MEL), 1-tetradecanol (TD) + MES, TD + MEP, and TD + MEL. Also, Composite PCMs consisting of organic and inorganic materials are on the rise. Jia et al. [17] prepared a new organic-inorganic composite PCM which is composed of trimethylolpropane (TMP), ammonium chloride ( $\mathrm{NH} 4 \mathrm{Cl})$, and $\mathrm{H} 2 \mathrm{O}$, for the application of cold chain logistic. As shown in Table 1, different combinations of solid-liquid materials and

\footnotetext{
*Corresponding author's e-mail: jxie@shou.edu.cn
} 
different post-treatments allow different phase transition temperatures to be obtained for different applications.

Table1. Studies on solid-liquid PCMs.

\begin{tabular}{|c|c|c|c|c|c|}
\hline Time & Author & PCMs & $\begin{array}{l}\text { Phase } \\
\text { change } \\
\text { temperature } \\
\left({ }^{\circ} \mathrm{C}\right)\end{array}$ & $\begin{array}{l}\text { Latent } \\
\text { heat } \\
(\mathrm{J} / \mathrm{g})\end{array}$ & Features \\
\hline 2019 & {$[18]$} & $\mathrm{NaCl}, \mathrm{K}_{2} \mathrm{CO}_{3}, \mathrm{KCl}$ & $-25 \sim-23$ & 200 & $\begin{array}{l}\text { Develop a low temperature ( }-25 \text { to } \\
\left.23^{\circ} \mathrm{C}\right) \text { composite } \mathrm{PCM} \text { and analysis of } \\
\text { its physical properties. }\end{array}$ \\
\hline 2019 & [19] & $\begin{array}{l}\text { calcium stearoyl lactylates } \\
\text { (CSLs) }\end{array}$ & $25.47 \sim 40.45$ & $\begin{array}{l}55.5 \sim 84 \\
.5\end{array}$ & $\begin{array}{l}\text { A series of homologous series of } \\
\text { calcium stearoyl lactates (CSLs) with } \\
\text { the same phase transition temperature } \\
\text { was synthesized by esterification } \\
\text { between stearic acid (SA) and lactic } \\
\text { acid (LA). }\end{array}$ \\
\hline 2019 & {$[20]$} & $\begin{array}{c}\text { sorbitol } \\
\text { aqueous solution }(\mathrm{C} 6 \mathrm{H} 14 \mathrm{O} 6)\end{array}$ & -2.9 & 293.8 & $\begin{array}{l}\text { Thermal and physical properties were } \\
\text { optimized using nanomaterials. }\end{array}$ \\
\hline 2018 & {$[21]$} & $\begin{array}{l}\text { Nano-TiO2 / wax composite } \\
\text { emulsion(NTWCEPCM) }\end{array}$ & 24.9 & 62.53 & $\begin{array}{l}\text { Dispersion stability, thermal } \\
\text { conductivity, and thermal cycling } \\
\text { stability of (NTWCEPCM) were } \\
\text { investigated. }\end{array}$ \\
\hline 2017 & {$[22]$} & CA, LA, MA, PA, SA & $17 \sim 56$ & $\begin{array}{c}127.2 \sim 2 \\
04.7\end{array}$ & $\begin{array}{l}\text { A series of binary and polyunsaturated } \\
\text { fatty acid co-crystal mass ratios and } \\
\text { phase transition temperatures and latent } \\
\text { heat of phase transition was studied. }\end{array}$ \\
\hline 2016 & {$[23]$} & tarch super absorbent polyme & 0.25 & 333.3 & $\begin{array}{l}\text { Preparation of tarch super absorbent } \\
\text { polyme with high water absorbency. }\end{array}$ \\
\hline 2015 & {$[24]$} & CA-PA-SA & 27.01 & 153.01 & $\begin{array}{l}\text { (MA)-stearic acid (SA), CA-MA- } \\
\text { palmitic acid (PA) to form a ternary } \\
\text { low-flux compound. }\end{array}$ \\
\hline 2015 & {$[25]$} & $\begin{array}{c}\text { Xylitol Penta Myristate/Xylitol } \\
\text { Penta Laurate }\end{array}$ & $50.28 / 43.53$ & $\begin{array}{l}199.50 / \\
184.71\end{array}$ & $\begin{array}{l}\text { Preparation of xylitol pentamyristate } \\
\text { and xylitol mayurate by the } \\
\text { esterification reaction. }\end{array}$ \\
\hline
\end{tabular}

\section{Active building energy efficiency measures}

PCMs could be used in building with active and passive energy conservation. Active building energy conservation measures refer to the operation of energy-consuming equipment to create a means of regulating the building environment to offset external disturbances, such as heating, air conditioning, ventilation, heat recovery. In the active building, PCMs is usually used in building equipment to reduce the power of equipment such as air conditioners and heat pumps, or cut down the energy demand during peak times.

\subsection{Phase change energy storage in the heat pump system}

The latent heat value of PCMs is much greater than water, and in heat pump systems, the application of PCMs can significantly reduce the volume of energy storage devices. Hirmiz et al.[26] added a heat transfer tank with 75\% PCM between the heat pump system and the building radiators in the geothermal heat pump heating system as shown in Figure 1. PCM makes it possible to reduce the size of the tank by $2 / 3$ and solves the problem of the insufficient peak heat output of ordinary ground source heat pumps. Plytaria et al.[27] designed and simulated a solar-assisted heat pump floor heating system for a building with a floor area of $100 \mathrm{~m} 2$. The PCM was placed between the floor and the heating system and different conditions were examined by varying the floor collection area, collector type, and insulation thickness. 


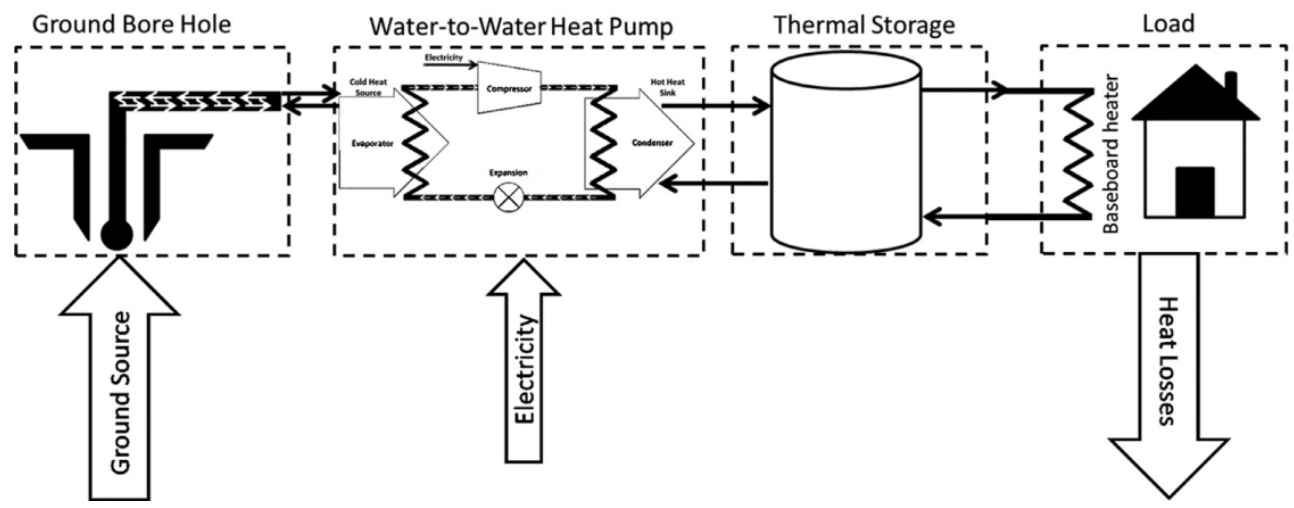

Fig 1. Ground source heat pump system with phase change energy storage tank [26].

\subsection{Phase change energy storage in the ventilation system}

Conduction or natural convection is the main method of heat transfer for PCMs and the heat transfer efficiency at a low level, so some researchers have used mechanical forced ventilation to improve the heat transfer efficiency. As shown in Figure2, a phase change ventilation system was developed, in which the PCM was wrapped and embedded in the wall and floor, and forced convection

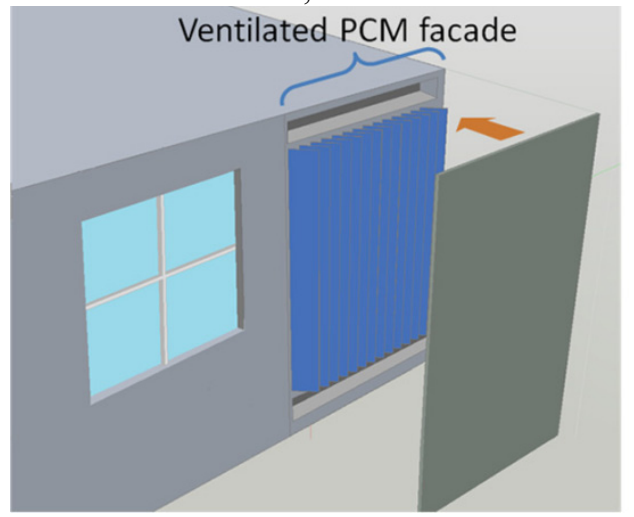

heat exchange between the PCM and the air was carried out using ventilation system. Such a system improves the heat transfer coefficient and increases the heat transfer area. It is a well-matched between the indoor environmental requirements and the working conditions of the phase change system. Phase-change system night cooling storage-daytime heat absorption mode is realized [28]. Ling[29] and Stazi[30] has also incorporated PCMs into ventilated phase change walls, which have been shown to absorb solar load, delay the peak temperature of the wall and improve thermal comfort in the room.

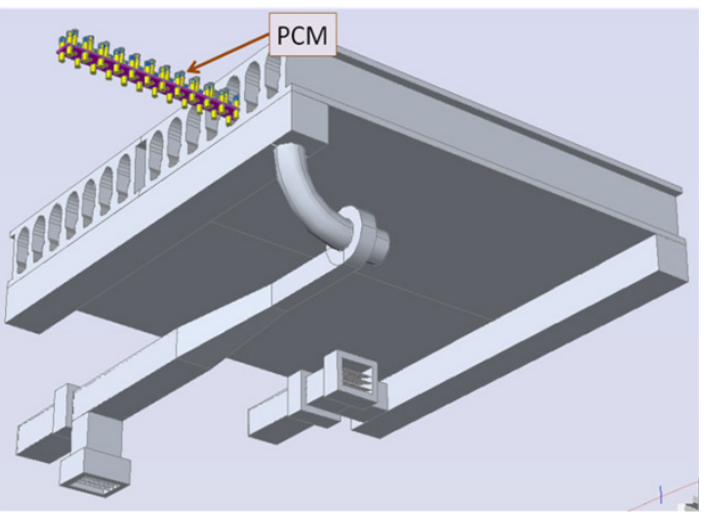

Fig 2. Phase-change ventilated walls and phase-change ventilated floor panels [28].

\subsection{Air conditioning energy recovery}

The phase change energy storage material can also recover the heat from the air conditioning condenser exhaust, as well as the cold from summer and the heat from the winter. This energy storage unit is used to recover the heat exhaust from the condenser for the building's heating needs when the air-conditioned building is simultaneously cooled and heated. Wang et al.[31] has developed an air conditioning unit that recovers condensed heat as shown in Figure 3, the unit's phase change heat storage tank and condenser are connected in parallel, and the condensing heat of the air conditioning unit can be recovered by switching the pipeline valve. A composite PCM consisting of single organic PCMs such as dodecanol, decanoic acid, tetradecanoic acid, lauric acid, and octadecanoic acid was proposed for the condensing heat recovery system of the air conditioner, and the effect of the phase change heat storage system on the compressor and the input power was investigated. Based on the dual requirements of the condensing temperature of the air conditioning system and the temperature of domestic hot water, Yuan et al.[32] proposed to use stearic acid, which has a phase change temperature of $54^{\circ} \mathrm{C}$ and a phase change latent heat of about $180 \mathrm{~J} / \mathrm{g}$, as a phase change heat storage material for the recovery of condensing heat from air conditioners 


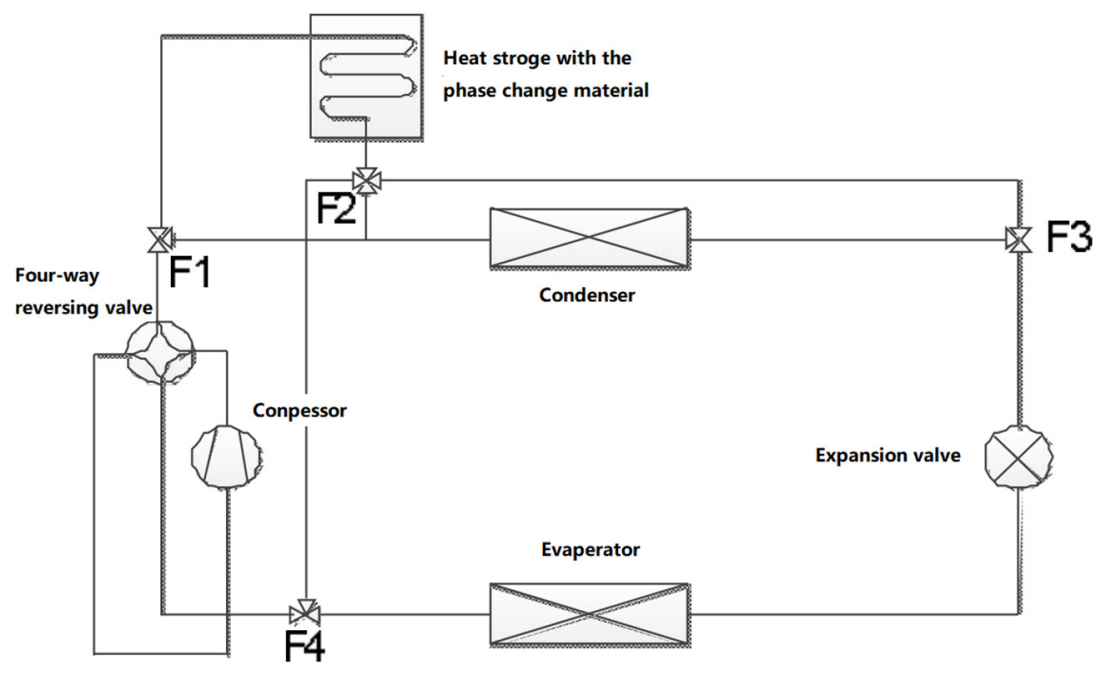

Fig 3. Air conditioning condensing heat recovery unit [31].

In addition, there are some measures of PCMs in air conditioning to remove peaks and fill valleys, such as airconditioning refrigeration storage technology. It is the use of electric-driven chillers to cool the night-time electricity consumption troughs and flat periods when the electric load is very low, and the use of phase change refrigeration storage materials to store the cold volume. During the peak period of electricity consumption, the stored cold capacity is released. The commonly used ice cold storage devices at home and abroad are used to separate the phase change material from the cold carrier and are encapsulated and coiled [33], as shown in Figure 4. The heat exchange reinforcement of the phase change material and the cold carrier in this device is the focus of research.

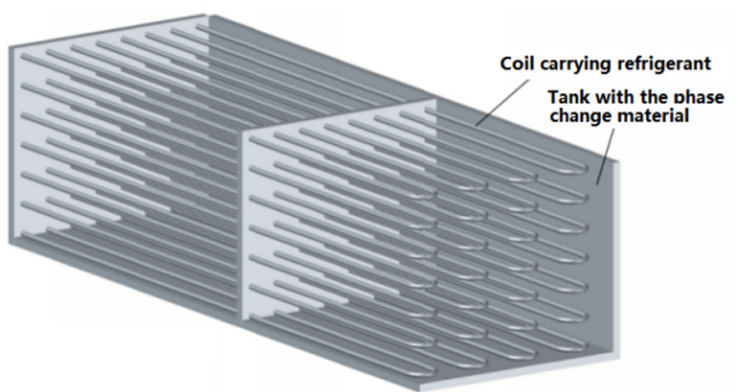

a) Coil-type refrigeration units

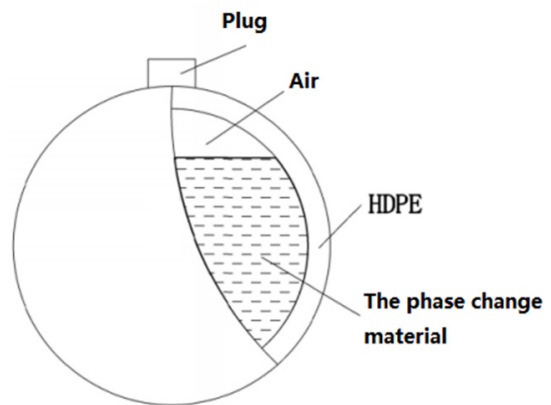

b) Ice pellet coolers [33]

Fig 4. A separate cooling storage device.

Also, some studies directly use PCMs such as slurry hydrates and encapsulated emulsions as cold carriers [34, 35]. For example, Zhu et al. [36] used gas hydrates as cold storage media and tetrahydrofuran hydrate with ndecanoic acid and dodecanol as cold storage materials and concluded that the organic composite phase change materials had the best promotion effect on hydrate formation when the amount of $1 \%$ was added, and the latent heat of phase change could reach $211.1 \mathrm{~J} / \mathrm{g}$.

\section{Conclusion}

PCMs are one of the most effective and on-going fields of research in terms of energy storage. PCMs are commonly used in building envelope materials and heat exchangers for building equipment, both as a passive measure to reduce building loads and as an active measure to reduce building energy consumption by using the latent heat of PCMs. However, it is not easy to combine with building materials due to the low latent heat of PCMs. A study on PCMs becomes more critical. This paper reviews the research results of PCMs and its application in building. Finally, the use of PCMs in various applications challenges faced, and future directions are also discussed.

In the future, the Encapsulation and design of energy storage devices is a focus of PCMs. Researchers should strengthen research on the encapsulation of PCMs, including encapsulation technology and encapsulation materials, and further research on how to apply new processes to composite with building materials. Development continues to develop screening of PCMs that can meet building energy efficiency standards and can be compounded with building materials with excellent performance and low cost.

\section{Reference}

1. Cui, Y., Xie, J., Liu, J.et al. (2017) A review on Phase Change material application in building. Advances in Mechanical Engineering, 9(6):1-15.

2. Zhang, J. J., Wang, Z. Y., Ding, M. Ming.et al. (2016) 
Influences of Facts Element with Energy Storage on Cascading Failures. Power System Protection and Control, 44(11):90-96.

3. Guan, Y., Chen, C., Ling, H. S. et al. (2013) Analysis of Heat Transfer Properties of Three-Layer Wall with Phase-Change Heat Storage in Solar Greenhouse. Transactions of the Chinese Society of Agricultural Engineering, 29(21): 166-173.

4. Yuan, Z. J., Zeng, H. Y. (2017) A Coupled Convective Commutative Value Method. Forum on Science and Technology in China. 2017: 54-55.

5. Liu, F., Huang, L, K., Chen, Y. Z.et al. (2018) Concurrence of Phase Transition and Grain Growth in Nanocrystalline Metallic Materials. Acta Metallurgica Sinica, 54(11):1525-1536.

6. Zhao, J. J., Zhou, J. H., Cui, Y. J.et al. (2019) Preparation and Thermal Properties of Nanoencapsulated Binary Phase Change Materials. Fine Chemicals, 36(06):1028-1035.

7. Hu, X. D., Gao, X. N., Li, D. L.et al. (2013) Performance of Paraffin/Expanded Graphite Composite Phase Change Materials. CIESC Journal, 64(10):3831-3837.

8. Guo, Y. L. (2019) Preparation and Properties of Phase Change Microcapsules/Silicone Rubber Composites. Southwest University of Science and Technology.

9. Wei, G. S., Xing, L. J., Xiao, Z. et al. (2014) Research Status and Selection of Phase Change Thermal Energy Storage Materials for CSP Systems. Proceedings of the CSEE, 34(03):325-335.

10. Zhang, R. Y. (2009) Phase Change Materials and Phase Change Energy Storage Technology. Science Press. Beijing.

11. Xie, P. C., Yan, H., Yu, R. S. et al. (2012) Advances in Solid-Liquid Deformable Phase Change Materials Research. Discussion and Research, 2012(11):120123.

12. Wang, Z., Chen, L. G., Fu, L. et al. (2012) Preparation and Properties of Paraffin /Active Carbon Phase Change Materials. Plastics, 41(01):74-76.

13. Souayfane, F., Fardoun, F., Biwole, P. et al. (2016) Phase change materials (PCM) for cooling applications in buildings: A review. Energy and Buildings, 129: 396-431.

14. Sun, W. C., Feng, J. X., Zhang, Z. G. et al. (2020) Research progress of phase change heat storage technology for passive energy conservation in buildings. Chemical Industry and Engineering Progress, 39(5):1-14.

15. Wei, D. W., Han, S. N., Shen, X. (2016) Solid-liquid phase equilibria of (n-octadecane with myristic, and palmitic acid) binary mixtures used as phase change materials (PCMs). Journal Of Chemical Thermodynamics, 101: 7-11.

16. Ghadim, H. B., Shahbaz, K., Al-Shannaq, R. et al. (2019) Binary mixtures of fatty alcohols and fatty acid esters as novel solid-liquid phase change materials. International Journal of Energy Research,

\section{3:8536-8547}

17. Jia, P. Y., Wu, W. D., Wang, Y. C. et al. (2019) Preparation and Thermophysical Property Optimization of A New Composite Phase Change Material For Cold Storage. Journal of Chemical Industry and Engineering (China), 70: 2758-2765.

18. Ban, F. C., Lu, L. X., Pan, L. et al. (2019) Preparation and Performance of freeze type composite phase change material. New Chemical Materials, 47(05):218-221+226.

19. Jiang, Y. Y., Zhou, C. L., Liu, Z.M. et al. (2019) Facile Preparation of Calcium Stearoyl Lactylate as SolidLiquid Phase Change Materials with Improved Form Stability and Adjustable Phase Transition Temperature for Thermal Comfort. Environmental Progress \& Sustainable Energy, 38(4): 1944-7442.

20. Jia, P. Y., Wu, W. D., Wang, Y. C. et al. (2019) Preparation of $0{ }^{\circ} \mathrm{C}$ Phase Change Material and Its Cold Storage Performance in Cold-Chain Logistics. Chemical Industry and Engineering Progress, 38(06):2862-2869.

21. Zhang, P., Zhang, G. Q., Tang, Y. N. et al. (2018) Preparation of Phase Change Material Based on Nano-TiO2 /wax Emulsion and Its Thermal Conductive Properties. Journal of Hunan University, 45(12):117-123.

22. Ke, H.Z. (2017) Phase diagrams, eutectic mass ratios and thermal energy storage properties of multiple fatty acid eutectics as novel solid-liquid phase change materials for storage and retrieval of thermal energy. Applied Thermal Engineering, 113: 1319-1331.

23. Liang, T., Lu, L. X., Qiu, X. L. et al. (2016) Study on preparation of starch super absorbent polymer and property as a phase change cold storage material. New Chemical Materials, 44(06):261-263.

24. Huang, X., Ying, D., Guo, Q. et al. (2015) Kinetic Study on Solid-Liquid Transitions of Fatty Acids Ternary Mixtures Phase Change Materials. New Chemical Materials, 43(08):149-151.

25. Bicer, A., Sari, A., Lafci, O. et al. (2015) Thermal Energy Storage Properties of Xylitol Penta Myristate and Xylitol Penta Laurate as Novel Solid-liquid Phase Change Materials. Energy Sources Part A-Recovery Utilization and Environmental Effects, 37: 2702-2709.

26. Hirmiz, R., Teamah, H. M., Lightstone, M.F., et al. (2019) Performance of heat pump integrated phase change material thermal storage for electric load shifting in building demand side management. Energy and Buildings, 190: 103-118.

27. Plytaria, M., Tzivanidis, C., Bellos, E. et al. (2018) Energetic investigation of solar assisted heat pump underfloor heating systems with and without phase change materials. Energy Conversion and Management, 173: 626-639.

28. Alvarez, S., Cabeza, L., Ruiz-Pardo, A. et al. (2013) Building integration of PCM for natural cooling of buildings. In: 12th International Conference on Energy Storage Innostock. Lleida, SPAIN. 514-522. 
29. Ling, H., Wang, L., Chen, Chao. (2019) Numerical investigations of optimal phase change material incorporated into ventilated walls. Energy, 172: 11871197.

30. Stazi, F., Mastrucci, A., Perna, C. (2012) The behavior of solar walls in residential buildings with different insulation levels: An experimental and numerical study. Energy and Buildings, 47: 217-229.

31. Wang, B. Y., Han, Z. T., Liu, S. G.et al. (2019) Properties of Organic Phase Change Materials for Air Conditioning Condensation Heat Recovery System. Building Energy \& Environment, 38:50-52.

32. Yuan, Y. G. (2015) An experimental research for the heat storage property of recovery phase change device used for condensing heat in air-conditioning system. Southwest Jiaotong University.

33. Wan C. (2010) Numerical and Experimental Study on Ice-On-Coil Storage Tank. D. Central South University.

34. Li, Z. N., Zhao, Y. J., Fan, Y. R. (2018) Research progress of phase change cold storage slurry materials. Chemical Industry and Engineering Progress, 37(S1): 108-116.

35. Zhu, M. G. (2018) The Study of Effect of Organic Phase Change Materials on Hydrate Formation. Suzhou University of Science and Technology.

36. Zhu, M. G., Sun, Z. G., Yang, M. M.et al. (2017) Experimental Study on Promoting HCFC-141b Hydrate Formation with Organic Phase Change Material. Chemical Industry and Engineering Progress, 36 :1265-1269. 